\title{
Role of Adversity Quotient (AQ) on Perceived Stress of Managers: with specific reference to AQ Dimensions
}

\author{
Somaratne C.S.N. ${ }^{1}$, Jayawardena L. N. A. C. ${ }^{2}$ and Perera B.M.K. ${ }^{3}$ \\ 1, ${ }^{3}$ Postgraduate Institute of Agriculture, University of Peradeniya, Sri Lanka, \\ ${ }^{2}$ Department of Agricultural Extension, Faculty of Agriculture, University of \\ Peradeniya, Sri Lanka \\ chamelisomaratne@yahoo.com¹, chandanacj@gmail.com², bmkperera@gmail.com³
}

\begin{abstract}
The aim of this study was to investigate the relationship between Adversity Quotient (AQ) and levels of perceived stress of middle-level managers employed in the Sri Lankan Non-Governmental Organisational (NGO) sector. Using a questionnaire survey 223 responses were collected. The data analysis included mean difference analysis and regression analysis. Age, work experience, and academic qualifications were found to significantly influence the level of AQ. However, gender and marital status recorded no such influence on AQ. Results further revealed higher AQ levels among managers of International NGOs. In addition, the study found that dimensions of AQ predict the variance in perceived stress. Only age and marital status among demographic factors explained the variance in perceived stress. The type of NGO was not a significant determinant in explaining the level of perceived stress. Further, AQ revealed no significant moderation between demographic factors and perceived stress. These empirical evidences signify that stress models can consider addition of AQ in future research. An integrated study among NGO, private, and public sector organisations is recommended. AQ serves as an important factor in training and development, selection process, and performance management.
\end{abstract}

Keywords: Adversity Quotient, Perceived Stress, Non-Governmental Organisations, Middle-level Managers

Copyright: (C) 2019 Somaratne C.S.N., Jayawardena L. N. A. C., Perera B.M.K. This is an open access article distributed under the Creative Commons Attribution License, which permits unrestricted use, distribution, and reproduction in any medium, provided the original work is properly cited.

Correspondence: chandanacj@gmail.com

ORCID of authors: Jayawardena L. N. A. C. - https://orcid.org/0000-0002-4816-7091

Somaratne C.S.N $\quad$ - https://orcid.org/0000-0001-6909-148X

DOI: http://doi.org/10.4038/kjm.v8i2.7603 


\section{Introduction}

Contemporary organizations - profit as well as non-profit are under pressure to work out new measures to meet these challenges for survival, continuity and growth. Especially, Non-Governmental Organisational (NGO) staff operates with limited resources, and work for longer hours in highly uncertain environmental circumstances (Hailey \& James, 2004). Pressures arising from work such as demands posed by organisational crises, restructuring due to financial limitations, and sudden policy changes, are some factors that create adversities leading to stress. Further, unrealistic demands placed by aid donors through emphasis on tight work schedules, timeframes, and rapid results lead to detrimental effects on credibility, confidence, and ability of NGO employees to pursue work goals (Kaplan, 2002). When employees perceive a discrepancy between the challenging conditions and their own capacities to fulfill the requirement, occupational stress comes into play. Thus, employees experience stress due to such pressures and complexities. Individual reaction to stressful conditions differs, as does the method of handling them. These individual differences in the capacity to bounce back from adversities is emphasized under the concept of Adversity Quotient (AQ) (Stoltz, 1997), an indicator of an individual's ability to cope with adversity. AQ presents a new paradigm gaining research interest in the organisational context (Phoolka \& Kaur, 2012). AQ in relation to stress, especially employee stress is less discussed (Shen, 2014). Several studies have explored the overall AQ of a person with only limited studies emphasizing the effect of its subdimensions (i.e., CORE) with other concepts. For instance, some studies have inquired AQ sub dimensions in relation to commitment to change (Langvardt, 2007), and demographic factors (i.e. age, and income group) (Paramanandam \& Shwetha, 2013). With regard to employee stress, further research is required to understand the effect of CORE dimensions. Existing literature provides conflicting evidence on the relationship between demographic factors and AQ (Huijuan, 2009). Hence, there is a need for further research to clarify the impact of demographic factors on AQ.

According to McMurray et al. (2010), research on non-profit organizations is relatively less when compared with other sectors. This is not different in the Sri Lankan context (Orujuela, 2005). For instance, only a limited number of studies have examined the stress among employees in the NGO sector (Gorbatenko, 2013). Similarly, studies on AQ in the organizational context have been predominantly based on the corporate sector, paying less attention to the non-profit sector (Langvardt, 2007). The literature on AQ and stress becomes further limited in the Sri Lankan context. In view of above limitations in literature, the following objectives were identified.

The overall objective of the study was to explore the relationship between AQ and perceived stress among middlelevel managers of the Sri Lankan NGO sector. Several specific objectives were identified for the study: a) examine the influence of demographic factors on $A Q, b)$ to examine the influence of type of $\mathrm{NGO}$ on $\mathrm{AQ}, \mathrm{c})$ to ascertain the extent to which AQ explains the variance in stress, d) to ascertain the extent to which demographic factors, and which type of NGO in the presence of AQ explains the variance in stress, and f) to identify the moderation role of 
AQ on the relationship between demographic factors and perceived stress.

\section{Literature Review}

\section{Adversity Quotient}

AQ is an indicator of the ability of an individual to cope with adversities (Stoltz, 1997). The concept explains how well an individual responds in the face of misfortunes. Those with higher levels of AQ cope better with adversities by turning obstacles into opportunities (Stoltz, 1997). AQ consists of four dimensions represented by the acronym CORE. The four dimensions: Control, Ownership, Reach, and Endurance measure the level of AQ of an individual (Stoltz, 2000).

Control refers to the degree to which one perceives oneself as having control or influence over adverse situations. (Stoltz, 1997). This implies that a person's level of control influences the direction of the action, level of effort, and perseverance level of a person. Those who are relatively strong in this aspect tend to be proactive in adverse situations and are capable of turning adversity into opportunity (Stoltz, 2000). Such individuals will exert more effort with higher levels of resilience and perseverance in successfully attaining assigned tasks (Hung \& Chin, 2013).

Ownership refers to the degree of accountability one feels to improve the outcome of an adverse situation (Stoltz, 1997). A person with higher level of AQ will own or feel accountable for the adverse situation to face it with responsibility. Such a person will learn from experience, change the strategy of dealing with the situation, and take necessary action to accomplish the task.
This indicates the type of people who are responsible for their deeds, and make the outcomes of such events into learning opportunities (Stoltz, 2000).

Reach refers to the degree to which one perceives the impact of adversity into other areas of life (Stoltz, 1997). Those with higher AQ levels do not let adversity reach other facets of life. They consider adversity is specific and limited to one situation. Such individuals are well prepared to deal with adversity for they feel empowered (Stoltz, 2000).

Endurance refers to a person's perception of the duration the cause of adversity and the adversity itself will last (Stoltz, 1997). Those with high AQ perceive adversities as temporary and of having solutions to overcome them. Such individuals are optimistic and energetic in coping with adverse events (Stoltz, 2000).

According to Phoolka and Kaur (2012), several concepts such as resilience, longevity, performance, and response to change are found to be predictable with respect to a person's AQ level. AQ research has already been conducted on different samples and has proved to improve performance levels, leadership styles and practices, promotions, optimism, and commitment to change (Phoolka \& Kaur, 2012). AQ has been widely investigated in relation to a variety of constructs such as: academic performance or achievement (Huijuan, 2009), commitment to change during organisational transformation (Langvardt, 2007), resilience and job satisfaction (Paramanandam \& Shwetha, 2013), job embeddedness (De Gulan, Rosalia, \& Caballero, 2013), personal characteristics and job satisfaction (Bantang et al., 2013), and demographic factors (Shen, 2014). 


\section{Stress}

Stress is a growing concern for employees and employers in every field, worldwide. Pediwal (2011) emphasizes stress as a mismatch between organizational demands and individual employee capabilities. It is a person's psychological and physiological response to the perception of demands and challenges (Topper, 2007). Hence, stress is an outcome of an emotional response, when incongruence exists between the resources, abilities, and needs of an individual and the demands of a job. Causes that lead to stress could be a change, demand, constraint, risk or a challenge. Organisational, environmental, and personal factors are identified as major contributors of stress (Cook \& Hunsaker, 2001). Factors in the environment such as organisational downsizing, technological advances (Kendall et al., 2000), and the temporary nature of modern jobs have altered the characteristics of employment contract, affecting the comfort zones of employees in all sectors, with increased work pressures and levels of perceived stress (Otto \& Schmidt, 2007). These highly dynamic environmental conditions have created challenges for both contemporary profit and non-profit organisations. Similarly, in organizational settings, adaptation to jobs due to demands associated with tasks, roles and co-workers in the work environment contribute to stress levels of employees (Fox et al., 1993). Further, stress has become a spin-off of modern life as a result of balancing the demands of the workplace with personal or family life (Ornelas \& Kleiner, 2003). Thus, employees of all sectors, societies, and countries encounter numerous adversities in their personal and professional life.
According to Phoolka and Kaur (2012), people differ in their mental capacities. Hence, perception and coping of adversities is unique to each individual.

\section{Non-Governmental Organisational sector}

As defined by the World Bank, NGOs are groups or institutions that are mainly characterised as having cooperative or humanitarian focus in place of commercial objectives and are completely or largely independent of governments (Ghimire, 2003). NGOs which are foreign-based and operating in multiple countries are commonly known as International NGOs (INGO) while organisations that operate on a national scale are known as Local NGOs (LNGO) (Ghimire, 2003). All NGOs operating in Sri Lanka are registered under the Voluntary Social Services Organisations Act of 1980 as amended by the Voluntary Social Services Organisations Act No. 8 of 1998 and operate under the purview of the National Secretariat for NonGovernmental Organisations. Around the world, NGOs play a central role in influencing a society's response to social problems in various sectors such as sociocultural, economic, education, and environment (Ghimire, 2003). NGOs around the world operate under an increasingly volatile environment, facing natural and manmade disasters and economic and social challenges (Aldashev \& Verdier, 2009). Many NGOs compete for funds as well as for experienced and qualified staff since they are undercapitalised in responding to demands of the civil society in a progressively dynamic and competitive context (Trautmann et al., 2007). Similarly, irrespective of the growth in the Sri Lankan NGO sector during the war and tsunami periods, the present 
status records a considerable decline due to Sri Lanka being considered as a middle-income country, donors' priority shifting to other issues (e.g., refugee crises), and opportunistic politics (Akurugoda, Barrett \& Simpson, 2017). Hence, it is important to note that the social, economic, and political changes of the recent past have altered the conditions and have significantly affected the NGO sector organisations and employees.

\section{Methodology}

The research employed a positivistic approach. A sample of 223 middle-level managers from 24 LNGOs and 12 INGOs was selected using stratified random sampling method. Initially, 96 NGOs registered in Colombo and operating around Sri Lanka including 32 INGOs (stratum1) and 64 LNGOs (stratum 2) were identified. Proportion to the ratio of $1: 2,12$ INGOs and 24 LNGOs were randomly selected for the study. The unit of analysis of this study was middle-level managers. Due to unavailability of statistics on the number of middle-level managers employed in these organisations, all the middle-level managers in the randomly selected 36 organisations were surveyed. Data were collected through a survey questionnaire using established research instruments. AQ levels of respondents were examined utilizing the scale designed by Stoltz (2000) having 20 scenarios representing its four dimensions. The Perceived Stress Scale (PSS-14) by Cohen (1983) was used to examine the level of perceived stress among respondents. Demographic data (i.e. work experience, academic qualifications, marital status, age, gender) of respondents were obtained. Data analysis using SPSS 21 included descriptive analysis, mean difference and regression analysis. Data set was checked for missing values, outliers, and scale reliability. The z-scores of kurtosis and skewness, and ShapiroWilk test of normality were used to measure the distribution of data.

The research variables explored under the objectives of the study can be identified in the conceptual framework (Figure 1). 


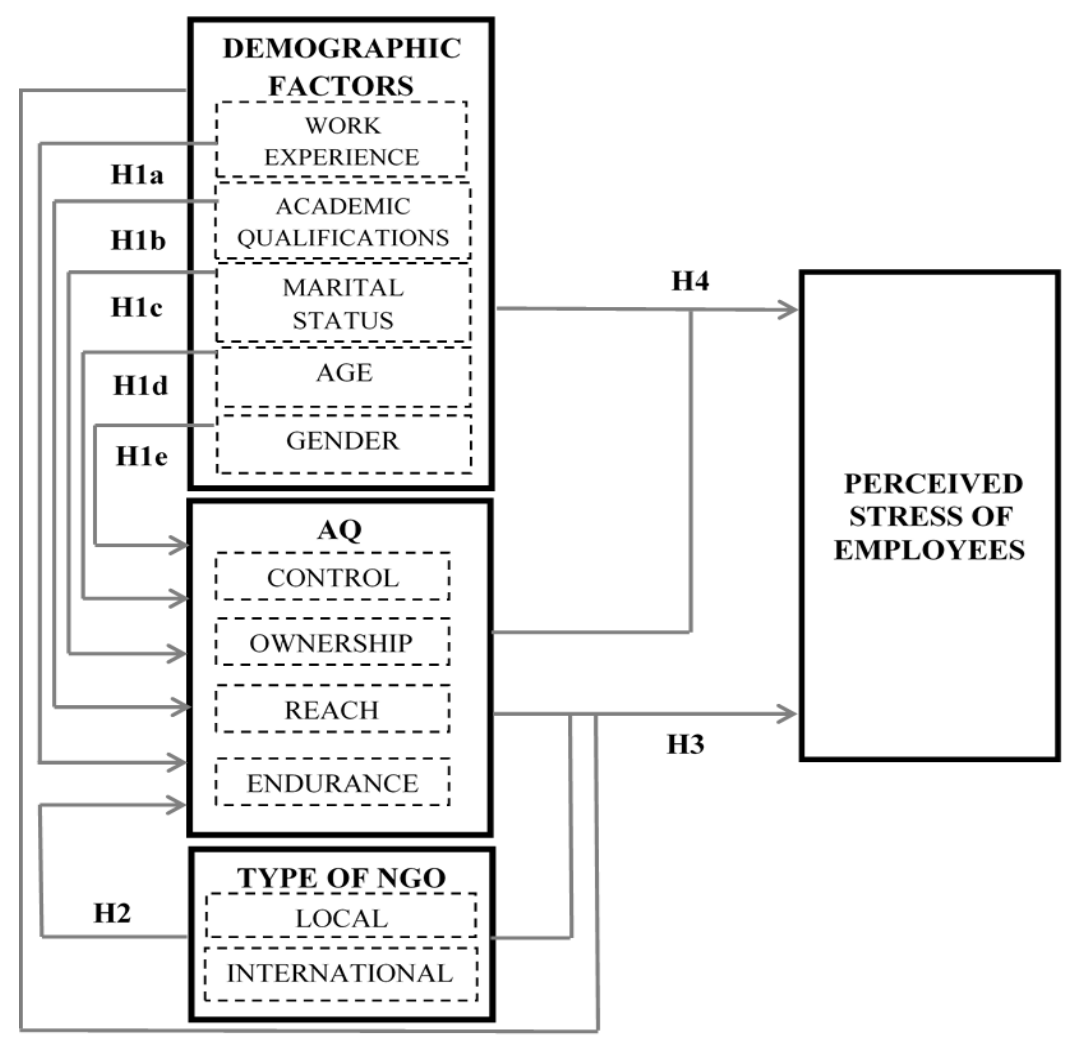

Figure 1 Conceptual Framework

\section{Results}

The total sample of 223 consisted of 159 men and 64 women. The majority was men in both INGOs and LNGOs. Overall age of respondents varied from 28 to 57 years. The majority $(45.3 \%)$ of middlelevel managers belonged to the age group of 35-44 years. The findings indicated that young and middle-aged middle managers were higher in number. The distribution of respondents by academic qualifications showed that the majority $(58.7 \%)$ of middle-level managers in the NGO sector has a bachelor's degree. Middle-level management of NGOs was highly educated as nearly $83 \%$ held graduate and/or postgraduate qualifications. Distribution of respondents based on work experience recorded the highest percentage $(58.3 \%)$ for middle-level managers in the experience category of 1 10 years. The number of middle-level managers decreased as the work experience increased. The distribution by marital status recorded that the majority $(64.6 \%)$ of the respondents was married, and represent local NGOs (52\%). Both scales PSS-14 and Adversity Response Profile were reliable with Cronbach's alpha values of 0.91 and 0.90 respectively. Respondents recorded a mean value of 26.92 for perceived stress from a maximum score of 56 with a standard deviation (SD) of 10.10. A mean value of 134.31 from a maximum score of 200 with an SD of 25.26 was scored for AQ. The zscores of skewness and kurtosis for all the variables were within the accepted range. Normal distribution of data was further 
confirmed by the Shapiro-Wilk test of normality where perceived stress recorded

\section{Relationship between AQ and Demographic Factors}

The first group of hypotheses explored the influence of demographic factors (work experience, academic qualifications, marital status, age, gender) on AQ.

\section{Work Experience and $A Q$ of Managers}

The relationship between the work experience of respondents and their AQ was examined.

One-way ANOVA test was conducted to identify whether there was a significant mean difference in $\mathrm{AQ}$ among different work experience groups. The assumption a significance value of 0.06 and AQ a significance value of 0.36 .

of homogeneity of variance was met as the Levene's test for equality of variances value 0.277 was greater than the level of significance of $p>0.05$. It was concluded that there is a significant difference of $A Q$ due to work experience. This results in the rejection of the null hypothesis.

The highest mean of 166.66 was recorded for the work experience category 21-30 years. Results of the Tukey-Kramer posthoc test (Table 1) revealed that there were significant differences of AQ among the work experience categories between 1-10 years and 11-20 years (18.26), 1-10 years and $21-30$ years (40.88), and 11-20 years and 21-30 years (22.61).

Table 1 AQ among Work Experience Categories (Post-hoc Test Results)

\begin{tabular}{|l|l|l|l|}
\hline Work Experience Group (years) & Mean Difference & Sig. \\
\hline \multirow{2}{*}{$1-10$} & $11-20$ & 18.26 & $0.000^{*}$ \\
\cline { 2 - 4 } & $21-30$ & 40.88 & $0.000^{*}$ \\
\hline $11-20$ & $21-30$ & 22.61 & $0.014^{*}$ \\
\hline
\end{tabular}

Note. ${ }^{*} p<0.05$ significant mean differences

Source: Survey Data

\section{Academic Qualifications and $A Q$ of Managers}

The relationship between the Academic Qualifications of respondents and their AQ was examined.

$\mathrm{H} 1 \mathrm{~b}_{0}$ : There is no significant difference in respondents' AQ due to academic qualifications

One-way ANOVA test was conducted to identify whether there was significant mean difference in AQ due to academic qualifications. The assumption of homogeneity of variance was met as the Levene's test for equality of variances value 0.422 was greater than the level of significance $(p>0.05)$. The $\mathrm{p}$-value of one-way ANOVA test was lower than the level of significance $(p>0.05)$. It was concluded that there is a significant difference in $\mathrm{AQ}$ due to academic qualifications. The null hypothesis was rejected.

Respondents of holders of postgraduate qualifications recorded the highest mean of 148.25 for AQ. Results of the TukeyKramer post-hoc test (Table 2) revealed that there were significant differences of AQ between postgraduate and secondary qualifications (20.25), postgraduate and graduate qualifications (16.38), and postgraduate and professional qualifications (31.67). 
Table 2 Difference of AQ among Academic Qualifications (Post-hoc Test Results)

\begin{tabular}{|l|l|l|l|}
\hline \multicolumn{2}{|c|}{ Academic Qualification } & Mean Difference & \multicolumn{1}{c|}{ Sig. } \\
\hline \multirow{4}{*}{ Postgraduate } & Secondary & 20.25 & $0.006^{*}$ \\
\cline { 2 - 4 } & Graduate & 16.38 & $0.000^{*}$ \\
\cline { 2 - 4 } & $\begin{array}{l}\text { Professional } \\
\text { Qualifications }\end{array}$ & 31.67 & $0.000^{*}$ \\
\hline
\end{tabular}

Note. ${ }^{*} p<0.05$ significant mean differences

Source: Survey Data

\section{Marital Status and $A Q$ of Managers}

The relationship between the marital status of respondents and their AQ was examined.

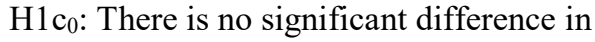
respondents' AQ due to marital status

One-way ANOVA test was conducted to identify whether there was a significant difference in AQ due to marital status. The assumption of homogeneity of variance was met as the Levene's test for equality of variances value 0.748 was greater than the level of significance $(p>0.05)$. The $p$ value of one-way ANOVA test was above the level of significance $(p>0.05)$. It was concluded that there is no significant mean difference in AQ due to marital status. Therefore, the null hypothesis was rejected.

\section{Age and $A Q$ of Managers}

The relationship between the age of respondents and their AQ was examined. $\mathrm{H} 1 \mathrm{~d}_{0}$ : There is no significant difference in respondents' AQ due to age
One-way ANOVA test was conducted to identify whether there was a significant difference among the mean values of different age groups. The assumption of homogeneity of variance was met as the Levene's test for equality of variances value 0.221 was greater than the level of significance $(p>0.05)$. The $\mathrm{p}$-value of one-way ANOVA test was lower than the level of significance $(p>0.05)$. It can be concluded that there is a significant mean difference in AQ due to age. Therefore, the null hypothesis was rejected.

The analysis of means recorded the highest mean as 168.80 for the age group 55-64 years. According to results of Tukey-Kramer post-hoc test (refer Table 4), the highest significant mean difference was recorded between the age groups 25 34 years and 55-64 years (48.69), and the second highest mean difference (34.83) between 35-44 years and 55-64 years age groups, followed by significant mean differences between the age groups 25-34 years and 45-54 years (32.86), 35-44 years and 45-54 years (19.01), and between the age groups 25-34 years and 35-44 years (13.85).

Table 3 Mean Differences of AQ among Age Groups (Post-hoc Test Results)

\begin{tabular}{|l|l|l|l|}
\hline \multicolumn{2}{|l|}{ Age Group (Years) } & Mean Difference & Sig. \\
\hline \multirow{3}{*}{$25-34$} & $35-44$ & -13.85 & $0.000^{*}$ \\
\cline { 2 - 4 } & $45-54$ & -32.86 & $0.000^{*}$ \\
\cline { 2 - 4 } & $55-64$ & -48.69 & $0.000^{*}$ \\
\hline \multirow{3}{*}{$35-44$} & $45-54$ & -19.01 & $0.000^{*}$ \\
\cline { 2 - 4 } & $55-64$ & -34.83 & $0.000^{*}$ \\
\hline
\end{tabular}

Note. ${ }^{*} p<0.05$ significant mean differences

Source: Survey Data 


\section{Gender and $A Q$}

The relationship between the gender of respondents and their AQ was examined. $\mathrm{H}_{1} \mathrm{e}_{0}$ : There is no significant difference in respondents' AQ due to gender

The Independent-samples T-test was used to identify whether there was any significant difference in AQ among male and female middle-level managers. The assumption of homogeneity of variance was met as the Levene's test for equality of variances value 0.60 was greater than the level of significance $(p>0.05)$. Males indicated greater level of AQ $(M=135.93$, $S E=1.96)$ than females $(M=130.28, S E$

\section{Influence of Type of NGO on AQ}

$\mathrm{H} 2_{0}$ : There is no significant difference in respondents' AQ due to type of NGO

The Independent-samples T-test was used to identify whether there was any significant difference in AQ among LNGO and INGO middle-level managers. The assumption of homogeneity of variances was violated, as assessed by Levene's test for equality of variances ( $p<$ 0.45 ). Therefore, the results of the Welch t-test were interpreted. INGO managers indicated greater level of AQ $(M=141.86$, $S E=2.51)$ compared to LNGO managers $(M=127.34, S E=2.08)$. This difference was significant $t(210)=-4.44, p>0.05$ and represented an effect of $r=0.28$. It can be concluded that there is a significant difference in AQ between LNGO and INGO middle-level managers. Therefore, the null hypothesis was rejected.

\section{The Impact of AQ, Demographic Factors, and the Type of NGO on Perceived Stress}

$\mathrm{H} 3_{0}$ : AQ along with work experience, academic qualifications, marital status, age, gender, and type of NGO do not explain the variance of the perceived
$=3.29$ ). This difference was not significant $t(221)=-1.51, p>0.05$; however, it represented an effect of $r=$ 0.01 . It was concluded that there is no significant difference in respondents' AQ regardless of being male or female. Therefore, the null hypothesis cannot be rejected.

\section{Relationship between AQ and Type of NGO}

The second hypothesis of the study explored whether AQ levels differ among respondents due to the type of NGO (LNGO/INGO) they work in.

stress levels of NGO sector middle-level managers

In investigating the third hypothesis, hierarchical regression analysis was conducted to determine whether AQ, demographic factors, and the type of NGO predict the variance in perceived stress. As per the summary of results, Model 1, which consisted of the sub dimensions of AQ explained $64.3 \%\left(R^{2}=0.643\right)$ of the variation in perceived stress and the model was significant $(p<0.05)$. The addition of demographic factors (work experience, academic qualifications, marital status, age, gender) led to an increase in the predictability power of the model to $71 \%$ $\left(R^{2}=0.710\right)$ as indicated in Model 2. The Model 3 - full model that included sub dimensions of $\mathrm{AQ}$, demographic factors (work experience, academic qualifications, marital status, age, gender) and the type of NGO explained $71.1 \%\left(R^{2}\right.$ $=0.711)$ of variation in perceived stress. However, the addition of the type of NGO in Model 3 did not significantly improve the variance explained.

The Beta Coefficients of the overall model (model 3) indicated that when 'control' increases by one SD unit, it results in decrease in perceived stress of a middlelevel manager by 0.16 SD units. Similarly, increase of 'ownership' by one SD unit 
will cause a decrease of 0.31 SD units in perceived stress, 'reach' will cause 0.14 decrease in SD units of perceived stress, and 'endurance' will cause decrease in perceived stress by $0.11 \mathrm{SD}$ units. All relationships were found to be statistically significant at 0.05 level. However, except for age and single (marital status), all other variables (gender, work experience, academic qualifications, and type of NGO) had no statistically significant impact $(p>0.05)$ to explain the variance in perceived stress.

The results indicated that the four dimensions of AQ could explain $64.3 \%$ of the variance in perceived stress of middlelevel managers. However, besides age and marital status (i.e. single), other variables including gender, work experience, The moderation effect or the interaction between AQ and demographic factors was not significant $(p>0.05)$. Further, the moderation did not contribute to the overall model of explaining perceived stress level $\left(R^{2}\right.$ change $\left.=0.003, p>0.05\right)$. It can be concluded that AQ does not moderate the relationship between demographic factors and perceived stress. Therefore, the null hypothesis cannot be rejected. As an additional analysis, moderation of AQ was tested between each demographic factor and perceived stress. However, none of the relationships was significant.

\section{Discussion and Conclusions}

The purpose of this study was to investigate the relationship between perceived stress and AQ. Results indicated that AQ of male middle-level managers was not significantly different from that of the females. Results revealed that AQ levels of middle-level managers increase as work experience increases. This finding is contrasting to majority of previous findings that have concluded influence of work experience on AQ as not significant (Bantang et al., 2013). Shen (2014) has similar findings as this study that revealed academic qualifications, and type of NGO did not explain the variance in perceived stress. Therefore, the null hypothesis was not rejected.

\section{The Moderation Effect of AQ}

$\mathrm{H} 4_{0}$ : AQ does not moderate the relationship between demographic factors and perceived stress levels of NGO sector middle-level managers

In investigating the fourth hypothesis, regression-based PROCESS moderation was conducted to determine whether AQ has a moderating effect on the relationship between demographic factors and perceived stress.

difference in seniority results in a significant effect on levels of AQ indicating higher AQ levels for workers with longer work experience. It is probable that working in a particular context over a long period of time shapes an employee through training and extensive exposure. Shen (2014) states that ability to deal with adversities accumulates through life experience as well. These can result in the development of AQ capacity over the experience gained through years of service.

The level of academic qualifications revealed a significant effect on AQ where higher AQ levels were recorded for middle-level managers with higher academic qualifications. This finding strengthened the findings of Tripathi (2011) that identified a significant difference in AQ based on academic qualifications whereas studies by Bantang et al. (2013) have identified no such influence on AQ. Those who excel in the academic field are also found to be intelligent in dealing with adversities (Matore, Khairani, \& Razak, 2015). It can be assumed that AQ levels are higher among those with higher levels of education compared to that of lower levels of education. 
Marital status had no significant effect on AQ level of NGO managers. This strengthened the findings of studies by Bantang et al. (2013), and Paramanandam and Shwetha (2013) that concluded marital status of a person does not influence AQ. It is probable that AQ as a capability of a person to handle adversities across vast areas of life is not determined by the marital status of a person (Kumar, 2016).

Further, effect of gender on AQ has mixed findings in literature. De Gulan, Rosalia, and Caballero (2013) have found women to have higher mean scores of AQ compared to that of men. Findings of this study confirmed the majority of previous findings that indicated gender has no significant influence on the level of AQ of an individual (Bantang et al., 2013; Huijuan, 2009). A possible assertion is that AQ is a mental capacity that extends beyond the masculine and feminine traits of people.

This study revealed that the level of AQ of middle-level managers has increased with the increase in age. Some studies have indicated that age has no significant influence on AQ (Huijuan, 2009). Findings of this study indicated that the age group of 25 to 34 years had the lowest AQ levels while the age group 55 to 64 years had the highest levels of AQ. This finding was consistent with the findings of Paramanandam and Shwetha (2013) who found increase of AQ with age. It can be assumed that employees in higher age categories (with more exposure and experience overtime) have developed AQ abilities. Experiences and encounters have possibly made them more resilient and better able to cope with adversity, and thus superior to that of those in younger age groups. According to Stoltz (1997), the more hardships a person experiences, the more that person learns how to deal with them.

Results revealed a significant difference in AQ in terms of the type of NGO. INGO middle-level managers indicated a higher mean of 141.86 for AQ compared to middle-level managers of LNGOs. A possibility could be the difference between the two types of NGOs in terms of operations. Ghimire (2003) has highlighted that INGOs and LNGOs differ based on level of operations where the former category is headquartered in developed countries having operations both locally and in multiple countries, while the latter category operates on a national scale. This leads to the assumption that employees in INGOs deal with local and international situations, and hence are exposed to diverse opportunities to gain versatile experience in facing adversities. Although literature lacks evidence on the relationship of this classification with AQ, this finding contributes to enrich and provides new insights to AQ literature by exploring these two types of organisations in the same sector.

Further, AQ significantly explains the variance in perceived stress. Prakaew and Leesattrupai (2017) in a study conducted among students in Bangkok also have concluded that increase in AQ by one SD unit decreases stress by $0.66 \mathrm{SD}$ units. Further their study concluded that AQ significantly predicts $44 \%(R 2=0.440 ; p$ $<0.01)$ of variance in stress. This study indicates that perceived stress can be significantly predicted through their AQ. This implies that higher AQ levels lead to lower stress levels. As stated by Shen (2014), AQ develops the attitudes and capability of an individual to deal with stressful situations. Stoltz (2000) claims that individuals with higher AQ levels are able to control events that create adverse circumstances, have sense of accountability towards the outcome of the adverse situation, not allow the effect of adversities to reach other areas in life, and see adverse events as temporary. Therefore, it is probable that there is a strong inter-linkage between AQ level and perceived stress of middle-level managers as found by this study. 
Results further indicated that increase in age by one SD unit will cause 0.21 units decrease in perceived stress of middlelevel managers. This finding is consistent with the study by Trevisani (2015) on undergraduates that concluded increase in age by one standard deviation causes 0.22 decrease SD units of perceived stress of students. Age has been identified as an influential factor on stress (Dua, 1994). This study also identified that ability to deal with stressful events as age increases - indicating lower levels of perceived stress as age increases. In contrast, younger employees are found to experience higher levels of occupational stress since they are concerned about factors that determine the career ahead of them (Dua, 1994). The negative impact of age on stress can be a result of life and work experience of a person (Shen, 2014). Results also indicated that compared to those who are 'married', perceived stress of 'single' middle-level managers is less by $0.13 \mathrm{SD}$ units. Additionally, perceived stress of 'divorced' middle-level managers is less by $0.02 \mathrm{SD}$ units whereas 'widowed' middle-level managers experience more perceived stress by 0.01 SD units in comparison to perceived stress of 'married' middle-level managers. Nonetheless, results indicated that difference between 'married' and other groups of marital status ('divorced' and 'widowed') as not significant ( $p>0.05)$. However, all other variables viz., gender, work experience, and education qualifications, and also the type of NGO had no statistically significant impact ( $p>$ $0.05)$ to explain the variance in perceived stress of middle-level managers.

The finding of single employees experiencing lower stress compared to married employees has been highlighted by Vadivu (2017) who concluded that married managers experience higher levels of stress compared to single managers which supports the findings of this study. It can be assumed that those married have different life patterns, commitments, roles, and work/life obligations (Parveen, 2009) which could account for married managers to experience higher stress.

In line with the finding of this study, Vadivu (2017) also has concluded that there is no significant effect of gender, work experience, and education qualifications on stress in their respective studies. Although literature lack evidence on the effect of type of NGO on perceived stress, this study enriched existing literature by revealing there is no significant effect on perceived stress of middle-level managers due to the type of NGO.

Study has extended the existing literature by investigating the moderation effect of AQ. This implies that the effects of demographic factors and AQ should be considered in explaining perceived stress level of a person. Further, AQ does not change the direction of the relationship between demographic factors and perceived stress. For instance, even though an increase in age reduces the perceived stress level of a person (hypothesis 3), AQ neither changes the amount of stress reduced by age nor does it change the direction of that relationship.

These findings apprise the significance of AQ for both theory and practice. Future research on stress can consider AQ as an important construct in their models and practitioners could realise the significant role AQ plays in coping with adversities encountered at work. Organisations would benefit more by identifying and conducting programmes to strategically enhance the dimensions of AQ that are low among the employees, which would enhance their ability to cope with stress. Age, work experience, and academic qualifications have a significant influence on AQ levels of managers. Gender and marital status have no such significant influence. Organisations need to invest more training and development on young and inexperienced employees to develop 
their AQ capacities to cope with stress. Development of AQ can be utilised as a strategy to enhance overall organisational performance. INGO managers indicated a higher AQ level compared to LNGO managers. Hence, LNGOs need to rethink initiatives to increase the level of AQ among employees. Human resource management practices such as training and development, and performance management of employees would benefit through incorporation of AQ management practices.

Study has focussed only middle-level managers. Further insights can be gained from extending the investigation to other layers of management. In order to validate the results in other sectors, future research can conduct an integrated study among NGO, private, and public sector organisations. This will also facilitate the comparison of results among different sectors or industries.

\section{References}

Akurugoda, I. R., Barrett, P., \& Simpson, A. (2017). Different Levels of NGO Engagement and Reactions of the Government: Assessing the Sri Lankan Experience. Journal of Asian Development, 3(2), 103-119.

Aldashev, G., \& Verdier, T. (2009). When NGOs go global: Competition on international markets for development donations. Journal of International Economics, 79(2), 198-210.

Bantang, F. O. A. (2013). The Relationship Of Personal Characteristics And Job Satisfaction To Adversity Quotient Of Police Officers In Manila Police District [PDF file]. Retrieved from http://

www.peaklearning.com/documents/PEA K_GRI_caguingin.pdf

Cohen, S. (1986). Contrasting the Hassles Scale and the Perceived Stress Scale: Who is really measuring appraised stress? American Psychologist, 41, 716-718.

Cook, C.W., \& Hunsaker, P.L. (2001). Management and Organizational Behavior (3rd ed.). New York: McGraw Hill.

De Gulan, X. M. R., \& Caballero, R. T. R.G.C (2013). Adversity Quotient And Openness To Group Diversity As Predictors Of Job Embeddedness [PDF file]. Retrieved from http://www.peaklearning.com/documents /PEAK_GRI_deGulan.pdf

Dua, J. K. (1994), Job stressors and their effects on physical health, emotional health, and job satisfaction in a university, Journal of Educational Administration, 32(1), 59-78.

Fox, M. L., Dwyer, D. J., \& Ganster, D. C. (1993). Effects of stressful job demands and control on physiological and attitudinal outcomes in a hospital setting. Academy of Management Journal, 36(2), 289-318.

Ghimire, H. (2003). NGO/INGO centered approach: An alternative approach to development [PDF file]. Retrieved from https://www.nepjol.info/index.php/OPSA /article/view/1128

Gorbatenko, O. (2013). Managing occupational stress in human service nonprofit organizations in Mykolaiv, Ukraine. Organizations and Markets in Emerging Economies, 4(2)

Hailey, J. \& James, R. (2004). Trees die from the top: international perspectives on NGO leadership development, Voluntas, 15(4), $343-53$.

Huijuan, Z. (2009). The adversity quotient and academic performance among college students at St. Joseph's College, Quezon City [PDF file]. Retrieved from 
https://www.peaklearning.com/document s/PEAK_GRI_huijuan.pdf

Hung, M. L., \& Chin, P. L. (2013). Psychological contract breach and turnover intention: the moderating roles of adversity quotient and gender. Social Behavior and Personality: an international journal, 41(5), 843-859.

Kaplan, A. (2002). Development Practitioners and Social Process: Artists of the Invisible, London: Pluto Press.

Kumar, R. (2016). The Relationship of Personal Characteristics and Job Satisfaction to Adversity Quotient of Police Officers in Shimla District of Himachal Pradesh. International Journal of Economics \& Management Sciences 5, 331.

Kendall, E., Murphy, P., O’Neill, V., \& Bursnall, S. (2000). Occupational stress: Factors that contribute to its occurrence and effective management. Canberra, Australia: Centre for Human Services, Griffith University.

Langvardt, G. D. (2007). Resilience and commitment to change: a case study of a nonprofit organization [PDF file]. Retrieved from https://peaklearning.com/ documents/PEAK_GRI_langvardt.pdf

Matore, M. E. E. M., Khairani, A. Z., \& Razak, N. A. (2015). The Influence of AQ on the Academic Achievement among Malaysian Polytechnic Students. International Education Studies, 8(6), 69.

McMurray, A., Pirola-Merlo, A., Sarros, J., and Islam, M. (2010). Leadership, climate, psychological capital, commitment, and wellbeing in a nonprofit organisation. Leadership \& Organization Development Journal, 31(5), 436-457.

Ornelas, S., \& Kleiner, B. H. (2003), New Development in Managing Job Related
Stress, Journal of Equal Opportunities International, 2(5): 64-70.

Otto, K., \& Schmidt, S. (2007), Dealing with Stress in the Work Place, Journal of European Psychologists, 12(4): 272-282.

Paramanandam, P., \& Shwetha, R. (2013). Adversity Quotient (AQ) as a Predictor of Job Satisfaction. International Journal on Global Business Management \& Research, 1(2), 27.

Parveen, N. (2009). Investigating occupational stress among married and unmarried working women in Hyderabad city. Bahria Journal of Professional Psychology, 5, 21-37.

Pediwal, G. L. (2011). Excessive stress and its impact on employee behavior. Journal of Global Economy, 1(1), 13-40.

Phoolka, E. S., \& Kaur, N. (2012). Adversity Quotient: A new paradigm to explore. Contemporary Business Studies, 3(4), 67-78.

Prakaew U., \& Leesattrupai C., (2017). The Effects of Adversity Quotient Development Program on Stress in Mutthayomsuksa 3 Students in Bangkok Retrieved from http://25qt511nswfi49 iayd $31 \mathrm{ch} 80$-wpengine.netdna-ssl.com/wp

Shen, C. Y. (2014). The Relative Study of Gender Roles, and Job Stress and Adversity Quotient. Journal of Global Business Management, 10(1), 19.

Stoltz, P. G. (1997). Adversity quotient: Turning obstacles into opportunities. New York: Wiley.

Stoltz, P. G. (2000). Adversityquotient @ work: Make everyday challenges the key to your success - putting the principles of $A Q$ into action. New York: Wiley.

Topper, E. F. (2007), Stress in the Library, Journal of New Library, 108(11/12), 561564. 
Somaratne C.S.N., Jayawardena L. N. A. C., Perera B.M.K., KJM, 2019, 08 (02)

Trautmann, K., Maher, J. K., \& Motley, D. G. (2007). Learning strategies as predictors of transformational leadership: The case of nonprofit managers. Leadership \& Organization Development Journal, 28(3), 269-287.

Trevisani, C. (2015). A Correlational Study of Self-Regulated Learning, Stress and Mindfulness In Undergraduate Students [PDF file]. Retrieved from https://ir.lib.uwo.ca/cgi/viewcontent.cgi? article $=1017 \&$ context $=$ psychK_uht

Tripathi, S. (2011). Use of Adversity Quotient (AQ) in creating strong business leaders of tomorrow (Doctoral dissertation, Doctoral thesis, SNDT Women"s University) [PDF file]. Retrieved from http://shodhganga. inflibnet. ac. in/handle/10603/4619.

Vadivu ,T. S. (2017). A Study on Occupational Stress and Job Satisfaction among The Textile Managers In Tirupur, International Journal of Human Resource \& Industrial Research, 4(17), 38-50. 